\title{
308 - Personal protective factors in personal growth for nursing homes staff
}

Gema Pérez Rojo, Dra. en Psicología, Profesora Titular, Dpto de Psicología

Facultad de Medicina, Universidad CEU San Pablo, Campus de Montepríncipe (Boadilla del Monte, Madrid)

\section{Introduction}

Most studies about nursing homes staff are based on deficit models and focused on risks factors, however, when appealing to protective factors or individual strengths the publications are scarce. People differ in individual characteristics, abilities or skills which may be protective when managing adversities. Engaging and resolving positively stressors and other adversities gives people a sense of achievement, satisfaction, and helps to their personal growth, being this expressed through a major tolerance, compassion, forgiveness, and hope.

\section{Objective}

The aim of this study was to assess whether variables associated to the professionals (resilience, purpose in life, job content, job satisfaction and burnout) had a significant role in the personal growth of nursing homes staff in different job context situations (person-directed care and person-centred care).

Method: 187 professionals working in nursing homes participated in this study.

\section{Results:}

The results showed that personal growth was explained by purpose in life, person-centred care, burnout self-realization, personhood, management and resilience, predicting $66 \%$ of variance $(F=23,22 ; p \leq .01)$.

\section{Conclusion:}

Individual variables of the staff predict personal growth, especially in person centred care. Personal growth has positive consequences on the caregiver but also on the care receiver. These results are consistent with the Person-Centered Care model that stresses the need of considering the humanistic aspects not only of the care-receiver but also of the caregiver.

This work was funded by the Spanish Ministry of Economy and Competitiveness (grant number PSI201679803-R). 